\title{
Interdisciplinary Research of Iron Casting Technologies in the Town of Juketaw during the Golden Horde Period
}

\author{
Eugenia Shaykhutdinova ${ }^{1-3}$, Rezida Khramchenkova ${ }^{1,2}$, Nabiullin Nail ${ }^{2}$, Belyaev Alexander ${ }^{2}$, Yanbaev \\ Ruslan $^{3}$, Airat Sitdikov ${ }^{1,2}$ \\ ${ }^{1}$ Kazan (Volga Region) Federal university, Kremlyevskaya str. 18, 420008 Kazan, Russian Federation \\ ${ }^{2}$ Archaeology Institute named after A. Kh. Khalikov of the Tatarstan Academy of Sciences, Butlerov str. 30, 420012 Kazan, Russian \\ Federation \\ ${ }^{3}$ Kazan National Research Technical University named after A.N.Tupolev - KAl, K.Marx str. 10, 420111 Kazan, Russian Federation
}

\begin{abstract}
The work features the results of interdisciplinary research of cast iron dishware fragments discovered in the territory of one of the largest towns of the Volga-Kama region in the Golden Horde period. The microstructure of cast iron samples and surface mapping have been studied using scanning electron microscopy (SEM), and the micro elemental composition was determined by emission spectral analysis (ESA). The characteristic features of the manufacturing technology have been revealed as a result of research of the elemental and phase composition across the area of the transverse fracture and longitudinal polished section. The results of SEM allowed to carry out a comparative analysis with archaeological material from the territory of Bolgar settlement - capital of the Bolgar Ulus of the Golden Horde. According to the results of micro elemental analysis, two groups of cast iron were determined with differences attributed to various sources of raw material.
\end{abstract}

Section: RESEARCH PAPER

Keywords: iron; metallurgy; Golden Horde; Volga Bolgaria; Bolgar; Juketaw; structure; chemical composition; ESA; SEM

Citation: Eugenia Shaykhutdinova, Rezida Khramchenkova, Nabiullin Nail, Belyaev Alexander, Yanbaev Ruslan, Airat Sitdikov, Interdisciplinary Research of Iron Casting Technologies in the Town of Juketaw during the Golden Horde Period, Acta IMEKO, vol. 6, no. 3, article 14, September 2017, identifier: IMEKOACTA-06 (2017)-03-14

Section Editor: Sabrina Grassini, Politecnico di Torino, Italy

Received March 15, 2017; In final form August 10, 2017; Published September 2017

Copyright: (C) 2017 IMEKO. This is an open-access article distributed under the terms of the Creative Commons Attribution 3.0 License, which permits unrestricted use, distribution, and reproduction in any medium, provided the original author and source are credited

Funding: The works were performed with the support of youth research grants of the Republic of Tatarstan (Tatarstan Academy of Science) (agreement 1458-f G 2016) "Archaeometric and arhaeotechnologic study cast iron ware as objects of material culture of the cities in Middle Volga region XIII - first half of XVI centuries"

Corresponding author: Eugenia Shaykhutdinova, e-mail: eugen.shaykhutdinova@gmail.com

\section{INTRODUCTION}

Volga (Volga-Kama) Bolgaria referred to by contemporaries as the "Country of Towns" is one of the first states in Eastern Europe which emerged in the 10th century within the territory of the Volga-Kama region and subsequently became a historic birthplace of many Turkic and Finno-Ugric people.

Juketaw is one of the most important, historically studied and localized towns of Volga Bolgaria. In the period of the Ulus of Jochi ("the Golden Horde") Juketaw experienced an age of prosperity. Its high economic potential presumably determined an administrative influence on certain territories. Russian chronicles of the early $15^{\text {th }}$ century mention a Bolgar princes together with "Jukotin" ones, and the two of them are seemingly equal according to the context. As a large handicraft centre, Juketaw had a rather peculiar material culture, and researchers suggest the existence of regional handicraft schools.

The 10-15 centuries archaeological complex of Juketaw is located on the Kama river $80 \mathrm{~km}$ upstream of its confluence with the Volga (Figure 1). It includes a compact historically related group of archaeological monuments - the Juketaw settlement, the Donaurovsk I (Krutogorsk) and II ancient villages, and necropolises. The first two monuments only existed in the Pre-Mongol period. During this period the Donaurovsk II ancient village was merely one of the town's 


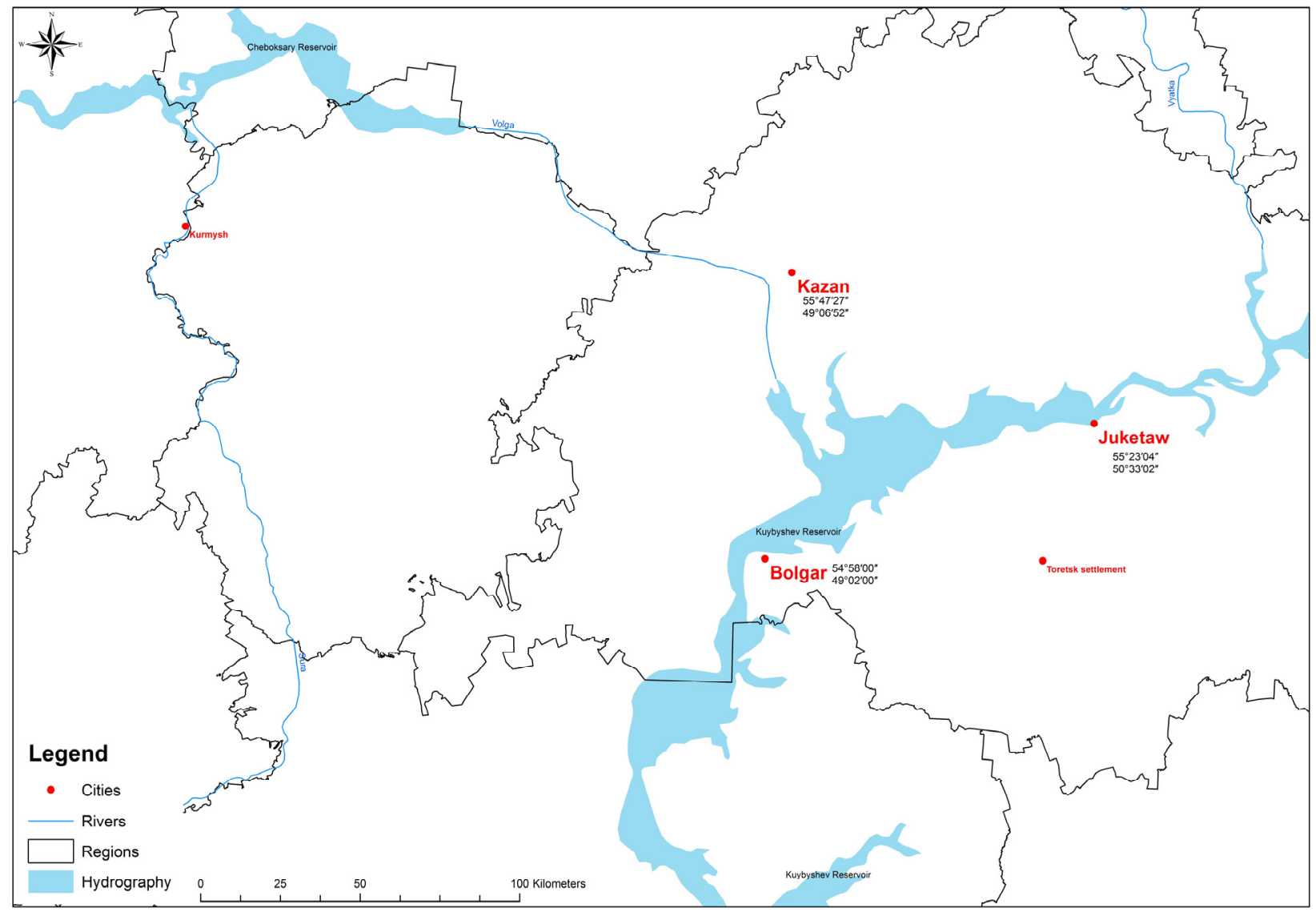

Figure 1. The town of Juketaw with respect to Bolgar town, Kazan and Moscow (the map has been compiled using an information system for archaeological research registering "ArchGIS" (Tatarstan, Russia [10]).

trading quarters, and in the Golden Horde period it became the major "open" part of the town [1]. Individual directions of Juketaw research are interconnected, specialized and involve the use of natural science techniques [2]-[5], [6], [7].

The research of iron casting has a wide historiography, and researchers indicate that the capabilities of not only morphological analysis, but also the research of the chemical composition of cast iron for the solution of issues on determination of iron casting centres within the Golden Horde are rather scarce [9]. Therefore, it is currently important to search for new methods of research using the capabilities of natural scientific methods. One of them is scanning electron microscopy (SEM), which according to research of cast iron from Bolgar [11], [12] allows to obtain more accurate data on the formation of its structure and the metal freezing process.

Ferrous and non-ferrous metallurgy production facilities and metal processing structures with clear traces of manufacturing (raw materials and blanks, slag and balls, defective products, production waste, etc.) were discovered on the territory of the Golden Horde Juketaw. The cultural layer of this area generally contains numerous traces of production activities, particularly slag and minor brick fragments; in the overall complex of cultural remains there is a significant number of tools and implements for craftsmen. All known fragments of cast iron dishware have come from the territory of the Donaurovsk II settlement.

The research of Golden Horde cast iron discovered within Russia is generally fragmentary. The classical methods of metallography and emission spectral analysis (ESA) are most frequently used, as in [5]. However, the research of Bolgar cast iron [1], [6] demonstrated that scanning electron microscopy (SEM) allows to determine more subtle aspects of the structural formation of cast iron dishware in the process of metal freezing.

In this work six samples of cast iron dishware obtained during excavations of the archaeological remains of Juketaw have been studied using the SEM and ESA methods. A comparative analysis of SEM results was previously carried out using 15 samples of cast iron dishware discovered in the territory of the Bolgar settlement (Bolgar, the Tatarstan Republic, Russia) [11], [12].

\section{MATERIALS AND METHODS}

The majority of cast iron findings are excavated material (50 of 70 samples). Researched samples No.1-3 and 6 also fall into this category. A fragment (sample No.4) discovered at excavation VI (filling of structure 6) was included in the selection for analytical analysis. Besides this artefact, numerous fragments of non-glazed ceramics, shards of majolica and white clay glazed dishware was found. Iron knives, nails, piercing pliers, a lock, a key, a bronze hook, a copper pot, numerous cut-out pieces of copper plates and other production waste constitute the findings discovered at these excavations (Figure $2)$. At the same excavations in another similar open complex archaeologists discovered shards of cast iron dishware together with 1317, 1340 and 1360 coins. Besides, a similar research of a shard of a 17th-18th century cast iron pot discovered in the former territory of Juketaw (sample No.5) was carried out for 


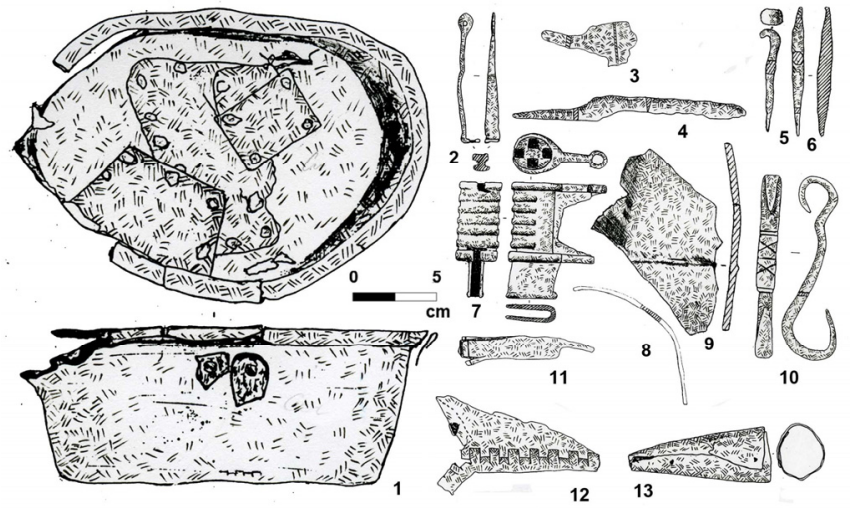

Figure 2. Samples of cultural remains from the filling of structure 6 at excavations VI of the Donaurovsk II settlement: 2-7 - iron, 1, 8, 10-13 copper and bronze, 9 - cast iron [2].

the purpose of comparing the technologies of handicraft and factory manufacture.

The major part of cast iron dishware has remained in the form of fragments due to its fragility (Figure 3). Researchers managed to restore the approximate dimensions of only several whole articles. For instance, the throat diameter at the rim of one of the fragments was $45 \mathrm{~cm}$, and another one $30 \mathrm{~cm}$. The height of the latter was approximately $15 \mathrm{~cm}$; such pots were 67 litres in volume. The transition from the throat to the rim is in most cases smooth (featureless), but there are samples with a clear (featured) transition. The inner surface of the rim in some cases features a ridge and can be tapered or straight. Grooves left by a casting form are traces on certain fragments. Some of the remaining dishware shards contain flat horizontal handles. According to all morphological attributes, cast iron pots from Juketaw fit rather well into existing classifications [8].

The samples are represented by pieces of metal dimensioned approximately $2.0 \times 1.0 \mathrm{~cm}$ obtained by means of chipping the initial pot walls. The thickness of the samples varies from 0.5 to $2.0 \mathrm{~cm}$.

SEM was used as a technique for studying the structure and chemical composition of the coins. Trace impurities of the

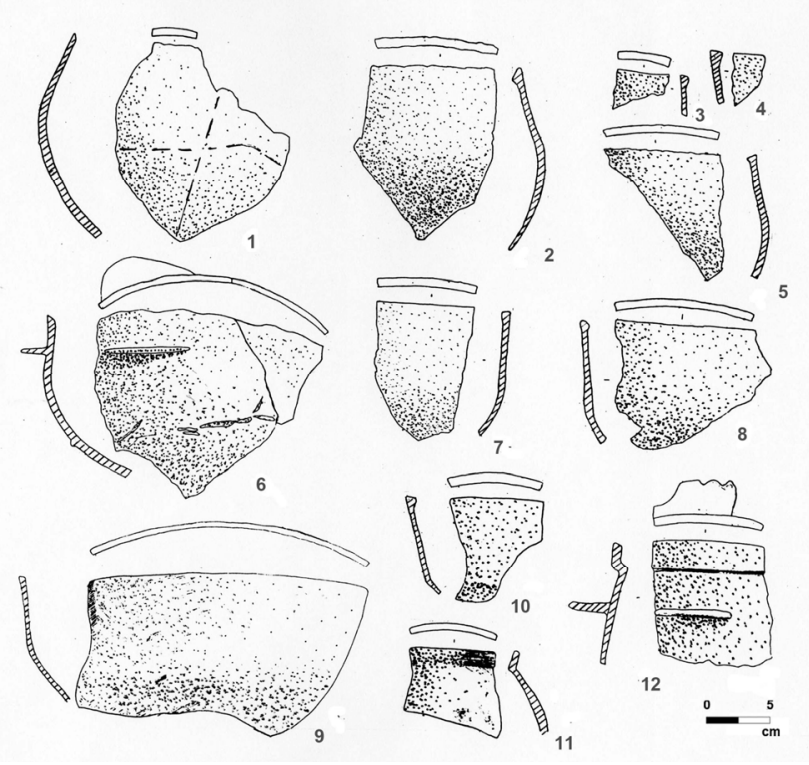

Figure 3. Samples of Juketaw cast iron dishware [2]. coin's alloy were investigated using the ESA technique.

SEM research was carried out on fractures and longitudinal polished sections of six samples. SEM analysis was conducted with the use of Axio Observer Z1, Axio Imager.Z2m and AURIGA CrossBeam with Inca X-Max energy-dispersive spectrometer at KNRTU-KAI (Kazan, Russian Federation). The electron-microscopic analysis was conducted using the VPSE mode (secondary electron detection in low vacuum mode) for the visualization of general surface morphology in panoramic shooting and the performance of quantitative and qualitative microprobe analysis $(20 \mathrm{kV}, 800 \mathrm{pA})$. The microprobe X-ray spectral analysis of samples on the basis of the INCA X-Max energy-dispersive spectrometer (with a sensitivity of $127 \mathrm{eV}$ ) includes the determination of sample composition, spectrum plotting and element distribution mapping. Images were obtained using the AxioObserver Z1 microscope in order to visualize the composition analysis sections [11]-[13].

The ESA technique applied to silver coins is described in [14]. The study was conducted at the Archaeology Institute named after A. Kh. Khalikov of the Tatarstan Academy of Sciences (Kazan, Russian Federation).

\section{RESULTS}

A comparative analysis of the surface morphology and shape of Bolgar and Juketaw cast iron dishware has not revealed significant differences, except for the cast iron sample dated the 17th-18th centuries.

Sample No.1 has a distinct composition of pig iron. Carbon is rather uniformly distributed across the entire area of the fracture. A double magnification of the studied area given in Figure $4 a$ demonstrates the presence of distinct minor peaks of increased carbon content. It signifies that carbon is present in the alloy both in bonded and free state.

A distribution of phosphorus along the borders of grains confirms its laminar structure (Figure $4 b$ ). The peaks of high
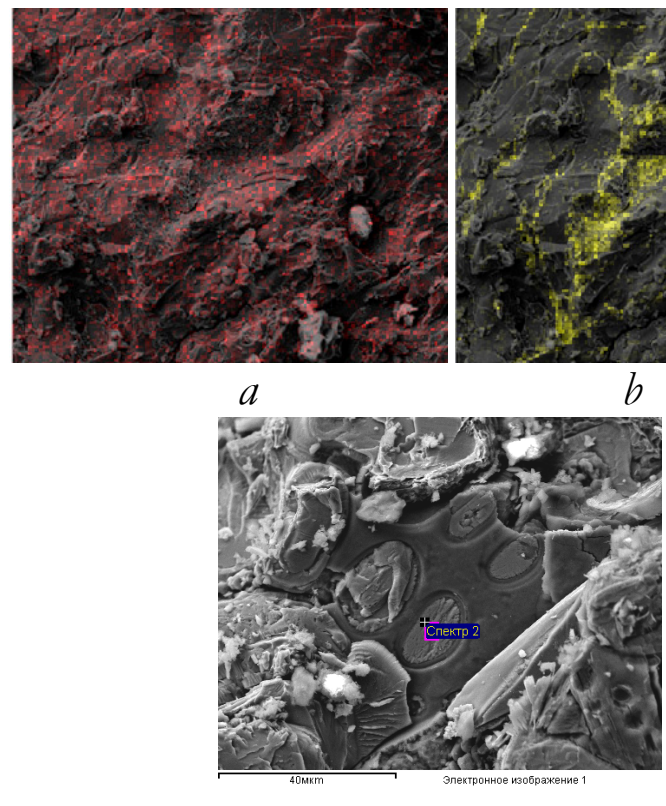

c

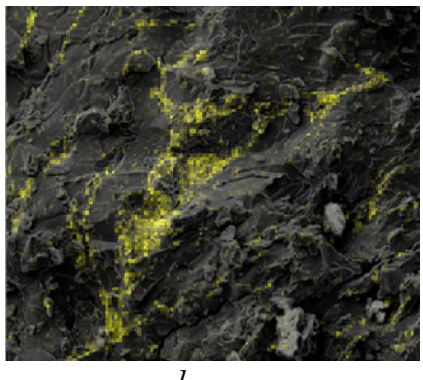

Figure 4. Microstructure of sample No.1: $a$ - distribution of $C$ across the area of the sample; $b$ - distribution of $\mathrm{P}$ across the area of the sample; $c$ endogenous inclusions in the sample. 
oxygen and iron content correspond to pale inclusions within the structure and presumably signify the formation of grains with predominant ferrite content.

Manganese and iron are evenly distributed with occasional peaks with up to $5.00 \%$ content visible upon double magnification. Perhaps, iron ore with high manganese content were used in manufacturing. As the chemical affinity of manganese and sulphur is higher than in the Fe-S pair, a characteristic correlation of sulphur and manganese distribution is observed in the pair in areas with peak Mn content.

Silicon is uniformly distributed as well, but its content does not exceed $0.60 \%$, and at higher magnification its determination in the alloy is constrained (not exceeding 0.25 $\%)$. At the same time, its distribution in certain formations corresponds to that of oxygen and aluminium.

The fine structure indicates that the cast iron contained a great amount of crystallization centres. As a result, free graphite failed to form dendrites and crystallized in the form of minor plates evenly distributed across the entire volume of the article. Perhaps, the article was re-melted, for its structure is finely divided. This is also evidenced by occasional endogenous inclusions (Figure 4c).

High phosphorus content indicates the use of wooden fuel.

No shrinkage pores or porosity is observed in the article. Occasional cracks have presumably been formed as a result of the sampling process.

Sample No.2 features the composition of pig iron similar to sample No.1. Carbon is rather uniformly distributed across the entire area of the fracture. Carbon content is observed in the formation area of fine flaked graphite. Carbon is present both in bonded and free state (Figure $5 a$ ). Upon magnification of the sample, formations with the chemical composition of white cast iron of presumable hypoeutectic nature are observed (C 1.44\%).

The laminar structure of the sample No.2 is clearly visible from the distribution of phosphorus along the borders of grains confirms (Figure 5b). The peaks of high oxygen and iron content correspond to pale inclusions within the structure and

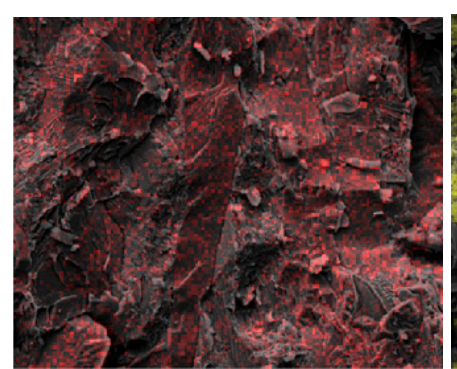

$a$

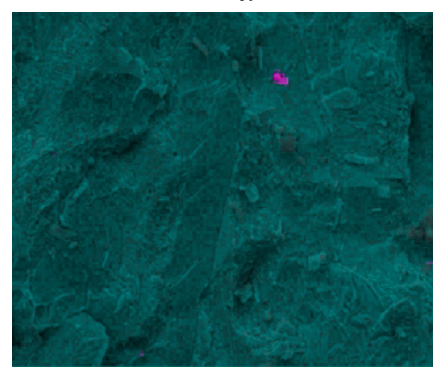

$c$

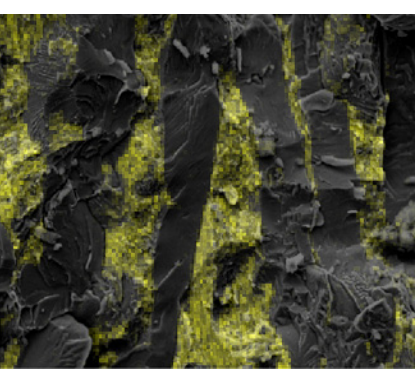

b

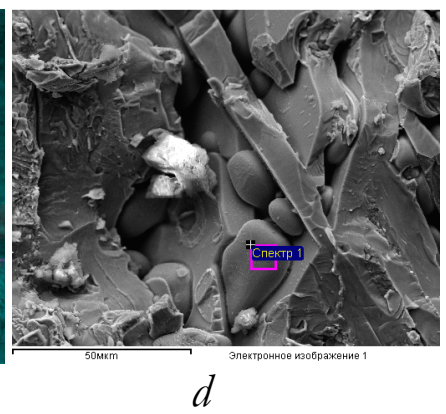

$d$ presumably signify the formation of grains with predominant ferrite content.

Manganese is unevenly distributed and in the distribution image the content of manganese corresponds to that of sulphur (Figure 5c). Unlike sample 133, the content of $\mathrm{Mn}$ in this sample does not exceed $0.10 \%$. Silicon inclusions do not correspond to traces of manganese (not exceeding $0.14 \%$ ), but correspond to that of oxygen.

Similarly to sample No.1, the structure is finely divided, but a more ordered laminar structure is observed. Perhaps, the article was re-melted, as its structure is finely divided, and not a large number of trace impurities is observed. It is signified by occasional endogenous inclusions (Figure $5 d$ ).

High phosphorus content indicates the use of wooden fuel.

No gas porosity is observed. Shrinkage processes at phase borders are visualized. Occasional cracks presumably formed as a result of the sampling process.

No.3 features a distinct pig iron composition. Carbon is unevenly distributed across the entire area of the fracture (Figure 6a), and a large number of hollow graphite channels is observed. The structure features flaked formations of grains similarly to samples No.1 and No.2 with a fine grained structure. However, they are deposited on plates with a coarser phase structure. Carbon content varies from $4.79 \%$ to $19.93 \%$.

The laminar structure of the sample No.3 is similar to sample No.1, 2 (Figure 6b), but its laminar distribution is not so clearly defined. The maximum phosphorus content is $1.95 \%$. The oxygen distribution is primarily concentrated inside coarse phase structural layers, which may correspond to the presence of ferrite phases in these areas.

Manganese is evenly distributed across the entire area of the fracture, and its distribution corresponds to sulphur content, although not all sulphur is in a bonded state. Unlike the two previous samples, this one features Mn content of about 0.25 $\%$. Silicon inclusions are evenly distributed and do not correspond to traces of manganese (not exceeding $0.07 \%$ ). Calcium deposits are observed, which are bonded not to the iron structural matrix, but to oxygen. The spectrum contains trace impurities of aluminium corresponding to silicon and oxygen content.

The structure is laminar with alternate fine and coarse phases. Perhaps a secondary metal with ore material was used as melting stock, or a fuel with high carbon content was utilized. This is also dignified by a minor content of phosphorus in the structure. No large endogenous inclusions are observed. No shrinkage pores or porosity is observed in the article.

Sample No.4 features a distinct composition of pig iron (similar to samples No.1-3). Carbon is rather evenly distributed

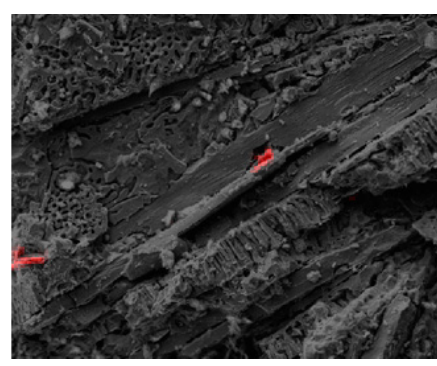

$a$

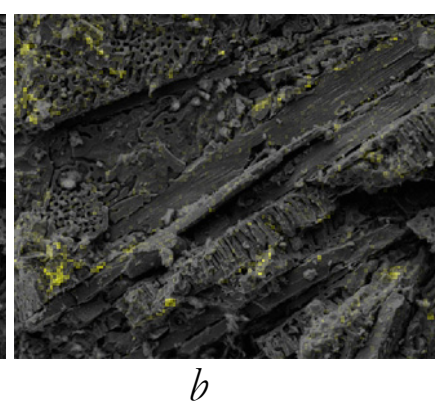

$b$
Figure 5. Microstructure of sample No.2: $a$ - distribution of C across the area of the sample; $b$ - distribution of $P$ across the area of the sample; $c$ distribution of iron (blue), manganese and sulphur (pink) across the area of sample fracture; $d$ - endogenous inclusions in the sample.
Figure 6. Microstructure of sample No.3: $a$ - distribution of $C$ across the area of the sample; $b$ - distribution of $\mathrm{P}$ across the area of the sample. 
across the entire area of the fracture (Figure $7 a$ ). Grains with white cast iron of hypoeutectic and pro-eutectic nature are observed with a C content of $1.65 \%$ and $5.39 \%, 4.01 \%$. At the same time, the structure contains grains with excess graphite content within the range of $7.17 \%$ to $17.54 \%$. This is confirmed by the presence of graphite channels. It signifies that carbon is present in the alloy both in bonded and free state.

A characteristic phosphorous distribution along the grain borders confirms a subtle laminar structure (Figure $7 b$ ). The average phosphorus content is approximately $0.24 \%$. The peaks of high oxygen and iron content within the structure presumably signify the formation of grains with predominant ferrite content.

The sulphur content is rather low. On the general image the total spectrum contains aluminium and nickel impurities. The peaks of silicon content correspond to aluminium and oxygen content. Calcium deposits correspond to certain oxidized areas. No manganese content is observed.

The structure is finely divided and chaotic. Subtle endogenous inclusions are observed upon magnification of the structural image in certain areas. High phosphorus content indicates the use of wooden fuel. Shrinkage processes and gas porosity are observed. The alloy contains a set of trace impurities varying from samples No.1-3 which indicates a different source of raw ore.

Sample No.5 features a distinct composition and structure of gray cast iron. Large flakes of graphite are radially distributed from the centres to the edges of grains, forming distinct dendrites (Figure $8 a$ ). The content of $\mathrm{C}$ varies from 9.27 to $79.99 \%$.

Phosphorous and sulphur concentrations are observed around grain borders (Figure 8b) with content not exceeding $1.67 \%$ and $0.07 \%$, respectively.

Ferrite grains are evenly distributed across the area of the

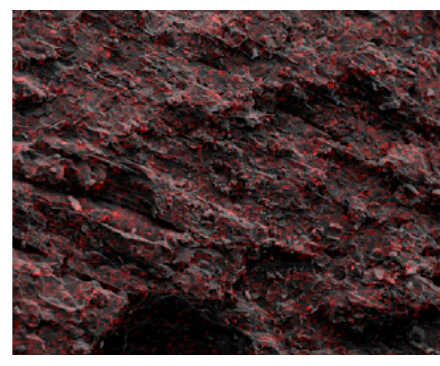

$a$

Figure 7. Microstructure of sample No.4: $a$ - distribution of $\mathrm{C}$ across the area of the sample; $b$-distribution of $P$ across the area of the sample.

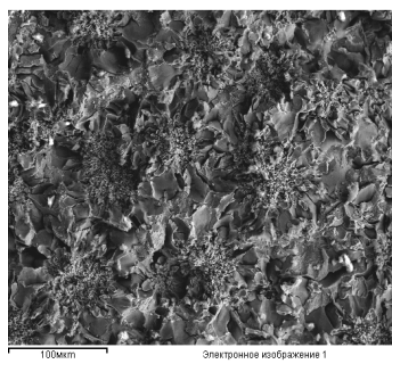

$a$

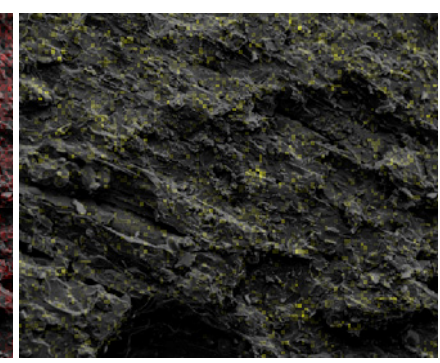

$b$ fracture in accordance with the locations of iron oxides. Partially oxidized areas correspond to the peaks of silicon content.

Sample No.5 is characterized by a uniform structure with distinct crystallization centres. The grains are round and feature distinct dendrite formations of graphite. The carbon distribution corresponds to that of silicon. The sulphur arrangement corresponds to the distribution pattern of manganese. It indicates a deliberate formation of the cast iron structure: deoxidation and modification. Besides, the ore source of melting stock contained a chrome impurity unlike samples No.1-4.

Sample No.6 features a distinct pig iron content (similar to samples No.1-4). Carbon is rather evenly distributed across the entire area of the fracture (Figure $9 a$ ). Minor peaks of increased carbon content are observed. The sample contains grains with hypereutectic cast iron with $C$ content of $3.5-4.0 \%$. Excess graphite is determined on all images through an increased carbon content and visualizes in the form of extra thin flakes. It means that carbon is present in the alloy both in bonded and free state.

The laminar structure of sample No.6 is similar to sample No.1-3 (Figure 9b). The average phosphorus content is approximately $1.97 \%$, varying in individual spectra from 0.19 $\%$ to $8.07 \%$. The oxidation is uniform and has a minor nature.

The sulphur content is relatively negligible. On the general image the total spectrum contains aluminium and nickel impurities. No manganese content is observed. The structure contains small amounts of silicon.

The structure is finely divided. Occasional endogenous inclusions are only visible in the walls of gas porosity (Figure $9 c$ ). The high phosphorus content indicates the use of wooden fuel. Shrinkage processes and gas porosity are observed. The alloy contains a set of trace impurities varying from samples No.1-3 but similar to sample No.4, which characterizes the source of raw ore. The alloy is most probably secondary.

Research of the microstructure on the basis of longitudinal polished sections confirms the results of transverse fracture
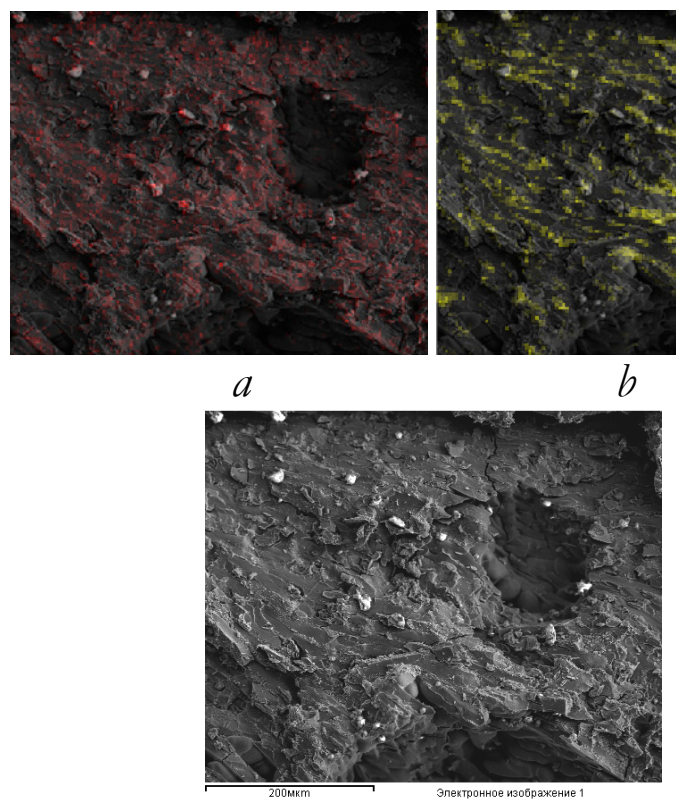

c
Figure 8. Microstructure of sample No.5: $a$ - microstructure of the sample; $b$ - distribution of $\mathrm{P}$ across the area of the sample.
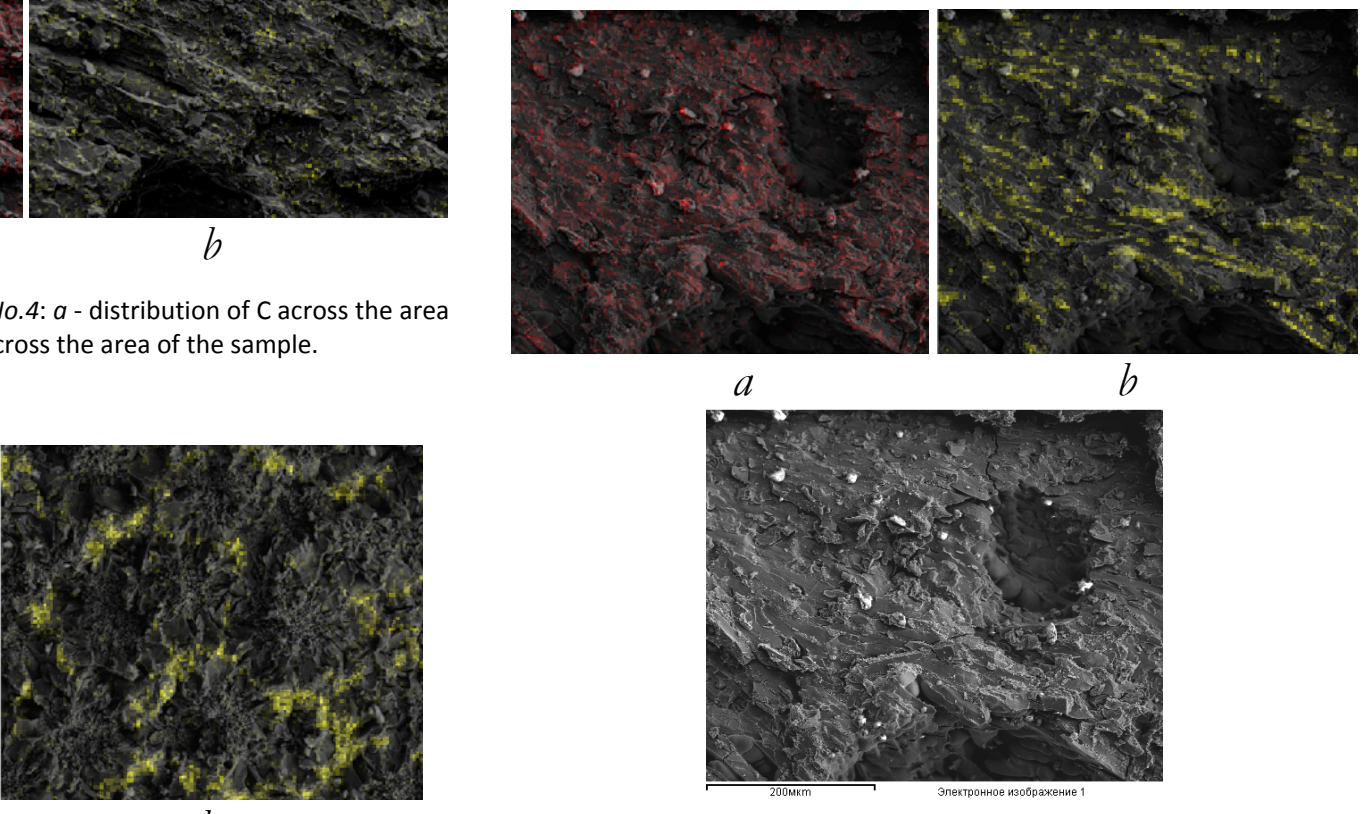

b
Figure 9. Microstructure of sample No.3: $a$ - distribution of $C$ across the area of the sample; $b$ - distribution of $\mathrm{P}$ across the area of the sample. 
research. However, it allows to discover additional trace impurities. For instance, zinc is traced together with the abovementioned impurities in sample No.2, and copper and zinc in sample No.5.

The overall chemical composition across the area of the studied sample is given in Table 1.

The total content of trace impurities has been determined using the ESA method (Table 2). A characteristic feature of Juketaw cast iron is a low concentration of zinc indicating either a high melting temperature of repeated re-melting of the material. Analysis results clearly demonstrate differences between the chemical composition of 14th century artefacts and the 17th-18th centuries sample. The factory boiler is characterized by a high content of manganese, nickel, chrome, tin, as well as silicon and titan. Whereas the first complex of elements indicates a different iron-containing raw material, Si and Ti suggest the use of various mineral components (clay or sand).

Earlier samples of cast iron are subdivided into the following two groups in terms of their chemical composition. The first group (samples No.1-3) is characterized by a high manganese and low silicon content. Cast iron No.3 is distinguished by lower concentrations of copper, nickel and cobalt, but also a higher silver concentration. The second group (samples No.4 and No.5) is characterized by a high aluminium and nickel content. Chlorine content is lower in these samples. The reverse correlation between $\mathrm{Ni}$ and $\mathrm{Cr}$ appears rather interesting and may mean various sources of iron. The low silicon and aluminium content in the first group probably characterizes either a specific technology or a special mineral raw material. The use of special coal raw material cannot be ruled out either.

\section{CONCLUSIONS}

The researched samples from Juketaw, with the exception of sample No.5, feature the composition of pig iron. The chaotic finely divided or laminar structure indicates an imperfect iron casting technology. The structure contains of complex phases. For instance, hypereutectic cast iron is adjoined by pro-eutectic

Table 1. Chemical composition of cast iron according to SEM results (weight, \%) [7].

\begin{tabular}{cccccccccccc}
\hline No. & $\mathrm{Fe}$ & $\mathrm{C}$ & $\mathrm{P}$ & $\mathrm{S}$ & $\mathrm{O}$ & $\mathrm{Al}$ & $\mathrm{Si}$ & $\mathrm{Cr}$ & $\mathrm{Ca}$ & $\mathrm{Mn}$ & $\mathrm{Ni}$ \\
\hline 1 & 83.56 & 10 & 1.13 & 0.26 & 4.41 & 0.12 & 0.25 & 0.04 & 0.06 & 0.16 & 0 \\
2 & 84.63 & 9.71 & 2.96 & 0.14 & 2.33 & 0 & 0.12 & 0 & 0 & 0.1 & 0 \\
3 & 75.8 & 12.1 & 0.41 & 0.14 & 10.85 & 0.06 & 0.07 & 0 & 0.27 & 0.24 & 0 \\
4 & 85.15 & 10.52 & 0.24 & 0.07 & 3.04 & 0.1 & 0.33 & 0 & 0.37 & 0 & 0.18 \\
5 & 85.86 & 8.45 & 1.97 & 0 & 3.36 & 0.08 & 0.11 & 0 & 0 & 0 & 0.16 \\
6 & 50.47 & 43.85 & 0.6 & 0.07 & 3.93 & 0 & 0.61 & 0.1 & 0 & 0.36 & 0 \\
\hline
\end{tabular}

cast iron, and at the same time features fine flaked graphite.

The phases can be generally subdivided into grains of white cast iron with graphite and a border layer with a complex micro-elemental and irregular composition. The latter demonstrates phosphorous and sulphur content, which allows to conclude that it is a certain origin of grain borders which hardened in the actual state. All structures feature a significant excess of graphite content distributed across the entire volume of the sample.

Unlike Bolgar cast iron [1], [6], samples from Juketaw do not feature a large number of casting defects. However, there are endogenous formations with various chemical and phase composition.

Strong segregation of chemical composition in all samples is accounted for by an imperfect technology, and no traces of structural adjustment were discovered.

Research of sample No.5 clearly demonstrates that the structure of cast iron was rather successfully adjusted as early as in the 17th-18th centuries: regular dendrites round in a single plane, pure graphite in the form of a series of flakes distributed around a single grain centre. At the same time, the centre of each dendrite continues to represent a chaotic mixture of ferrite, perlite and other chemical compounds.

Research of trace impurities in the structure of samples revealed an interesting characteristic feature - cast iron from Bolgar [11], [12] and Juketaw frequently contains aluminium, silicon and manganese impurities. At the same time, a superposition of obtained XRF-spectra revealed (SEM) that colour distributions of aluminium and silicon correspond to oxygen content. This peculiarity may indicate that sands were probably used as fusion agents. Perhaps these sands contained impurities in the form of manganese compounds, as in 9 out of 15 samples of Bolgar cast iron [1], [6] and 4 out of 5 samples of Juketaw cast iron contained manganese (Figure 10). Ti, Mg, Zn

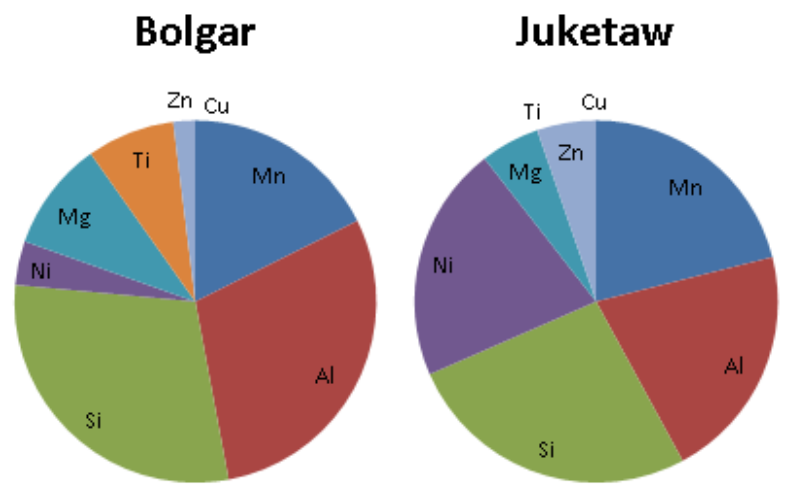

Figure 10. Distribution of micro-elements in samples discovered at excavations in Bolgar and Juketaw.

Table 2. Chemical composition of cast iron according to ESA results (weight, \%) (iron-based alloy with main alloying element carbon).

\begin{tabular}{cccccccccccccccccccccccccccccc}
\hline No. & $\mathrm{Ag}$ & $\mathrm{Al}$ & $\mathrm{As}$ & $\mathrm{Bi}$ & $\mathrm{Ca}$ & $\mathrm{Cr}$ & $\mathrm{Co}$ & $\mathrm{Cu}$ & $\mathrm{Mn}$ & $\mathrm{Na}$ & $\mathrm{Ni}$ & $\mathrm{P}$ & $\mathrm{Pb}$ & $\mathrm{Si}$ & $\mathrm{Sn}$ & $\mathrm{Ti}$ & $\mathrm{Zn}$ \\
\hline 1 & 0.00000020 & 0.00000002 & 0.0000050 & 0.0000015 & 0.000260 & 0.00000190 & 0.0000280 & 0.0000320 & 0.000450 & 0.000020 & 0.000041 & 0.0001700 & 0.0000031 & 0.00085 & 0.00000023 & 0.0000006 & 0.000020 \\
2 & 0.00000020 & 0.00000049 & 0.0000050 & 0.0000015 & 0.000275 & 0.00000160 & 0.0000350 & 0.0000390 & 0.000450 & 0.000010 & 0.000033 & 0.0002650 & 0.0000022 & 0.00045 & 0.0000024 & 0.0000007 & 0.000020 \\
3 & 0.00000056 & 0.00000110 & 0.0000045 & 0.0000016 & 0.000230 & 0.00000100 & 0.0000091 & 0.0000035 & 0.000750 & 0.000030 & 0.000013 & 0.0001850 & 0.0000019 & 0.00065 & 0.0000024 & 0.0000006 & 0.000015 \\
4 & 0.00000220 & 0.0000240 & 0.0000055 & 0.0000014 & 0.000165 & 0 & 0.0000280 & 0.00000280 & 0.000063 & 0.000045 & 0.000105 & 0.0002150 & 0.0000025 & 0.00600 & 0.00000021 & 0.0000009 & 0.000015 \\
6 & 0.00000180 & 0.0000280 & 0.0000060 & 0.0000016 & 0.000250 & 0.00000075 & 0.0000340 & 0.00000220 & 0.000045 & 0.000055 & 0.000118 & 0.0006250 & 0.0000022 & 0.00590 & 0.00000022 & 0.0000014 & 0.000020 \\
5 & 0.00000026 & 0.0000034 & 0.0000065 & 0.0000014 & 0.000295 & 0.00011600 & 0.0000370 & 0.0000390 & 0.001900 & 0.000015 & 0.000300 & 0.0001900 & 0.0000039 & 0.01100 & 0.0000460 & 0.0000029 & 0.000020 \\
\hline
\end{tabular}


and $\mathrm{Cu}$ impurities were discovered as a result of micro particle spectrum research.

Figure 10 demonstrates that cast iron from Juketaw is different from the Bolgar one in terms of nickel and titan impurities, but this may also be accounted for by a small selection of Juketaw samples.

A more accurate statistical determination of trace impurities requires a study of a larger selection, which is planned to be carried out in the future.

Almost all samples feature a large phosphorus content, which indicates that wooden fuel was used in iron casting. The micro-elemental composition of archaeological cast iron fragments signifies that not less than two handicraft centres were present, which used different raw material. A reference sample of the 17 th-18th cc. is very much different from medieval artefacts in terms of its chemical composition.

The presence of aluminium and silicon may be accounted for by the use of local iron-bearing ore - clay ironstone. Besides, the presence of these elements may be explained by the use of aluminium silicates as fusion agents. The content of titan, manganese, nickel, copper and other microelements may be accounted for by the fact that ore was supplemented by steel or cast iron scrap metal from other sources or regions during remelting. However, the more probable explanation may be the use of various sources of iron ores (bog ore, clay ironstone and iron sandstone), mineral fusion agents and coal raw material.

\section{REFERENCES}

[1] N. Nabiullin, "Juketaw - bulgar town on the Kama", Tatar.kn. izd-vo, Kazan, Russian Federation, 2011.

[2] G. Asylgarayeva, V.Bakhmatova, I. Gazimzyanov, L. Melnikov, J. Mukhametshin, N. Nabiullin, U. Semykin, R. Khramchenkova. "Results and prospects of research Juketaw". Proceedings of the IV (XX) archaeological congress, October 20-25, 2014, T. III, Kazan, pp. 444-446.

[3] V. Bakhmatova, About raw materials sources of ceramics "Dzhuketaw", Proceedings of the IV (XX) archaeological congress, October 20-25, 2014, T. IV, Kazan, pp. 119-121.

[4] V. Bakhmatova, N. Nabiullin, Possible origins of the unglazed «traditional» pottery (exemplified by Juketaw ceramic site of the 10th - 14th centuries), Philology and culture, 2013, №3 (33), pp. 232-235.

[5] I. Gazimzyanov, N. Nabiullin, "Anthropology of the population Juketaw (by materials of Donaurskiy cemetery)", Scientific notes of the Kazan University, A series of humanities, 2011, Vol. 153, Book 3, pp. 21-28.

[6] N. Nabiullin, R.Khramchenkova, "Glass jewellery of the Juketaw: morphology and chemical composition", Philology and culture, 2013, №3 (33), pp. 240-244.

[7] A. Petrenko, G. Asylgarayeva, N. Nabiullin, "Economic activity of Juketaw population according to archaeozoological materials", Philology and culture, 2012, №2 (28), pp. 278-281.

[8] K. Rudenko, Metal dishes of the Volga and the Kama region in the 8th-14th centuries, Izdatelstvo Reper, Kazan, Russian Federation, 2000.

[9] S. Ryazanov, Iron foundry in the European part of the Golden Horde (second half of the XII - XIV centuries), Dissertation of the candidate of historical sciences, Izhevsk, 2010.

[10] G. Sayfutdinova. Cartographic representation of archaeological monuments on the territory of the Republic of Tatarstan and selected regions of Russia, All-Russian scientific conference. International Year of Maps in Russia: combining space and time, Moscow. 2016, p. 257.

[11] E.Shaykhutdinova, A.Belyaev, R.Yanbaev, A.Sitdikov, A.Zinnatullin, "Iron casting in Volga Bolgaria in 14-15 cc.", Proc. of the 1st International Conference on Metrology for Archaeology, 2015, pp. 203-207.

[12] E.Shaykhutdinova, R.Yanbaev, R.Khramchenkova, A.Sitdikov, A.Belyaev, "The study of the cross fracture samples for the reconstruction process and performance characteristics of products iron foundry Volga Bulgaria", The casting processes: interregional collection of proceedings, Izd-vo Magnitjgorsk. gos. techn. un-ta im. G.I.Nosova, Magnitogorsk, Russian Federation, 2015, pp. 176-188.

[13] E. Shaykhutdinova, A. Belyaev, A. Sitdikov, R. Yanbaev, Archaeometric analysis of cast iron dishware from the towns of Volga Bolgaria: Bolgar and Juketaw, Proceedings of IMEKO International Conference on Metrology for Archaeology and Cultural Heritage (MetroArchaeo 2016). October 19 - 21, 2016. Torino, Italy. Pp. 270-273.

[14] Khramchenkova R., Degryse P., Sitdikov A., Kaisin A. Analytical studies of post medieval glass bottle marks from excavations at Kazan Kremlin (Russia). Journal of Archaeological Science: Reports. V.12, pp.25-27. 